1 Universidade Federal de São Paulo (Unifesp), Escola Paulista de Medicina, Departamento de Medicina Preventiva - São Paulo (SP), Brasil. soniam.melo2012@gmail. com

2 Universidade Federal de São Paulo (Unifesp), Escola Paulista de Medicina, Departamento de Medicina Preventiva - São Paulo (SP), Brasil. luizcecilio60@gmail.com

3 Universidade Federal de São Paulo (Unifesp), Escola Paulista de Medicina, Departamento de Medicina Preventiva - São Paulo (SP), Brasil. rbac48@gmail.com

\section{Nem sempre sim, nem sempre não: os encontros entre trabalhadores e usuários em uma unidade de saúde}

\author{
Not always yes, not always no: encounters between workers and users \\ at a health unit
}

Sonia Maria de Melo', Luiz Carlos de Oliveira Cecílio ${ }^{\mathbf{2}}$, Rosemarie Andreazza ${ }^{\mathbf{3}}$

RESUMO Uma peculiaridade do trabalho em saúde é sua característica de trabalho vivo em ato, dimensão micropolítica dificilmente captada pelos instrumentos de avaliação tradicionais. Assim, o estudo teve como objetivo caracterizar como os trabalhadores lidam com as demandas trazidas pelos usuários a uma Unidade Básica de Saúde (UBS), através da observação participante, em UBS 'tradicional' do município de São Paulo. As respostas dos trabalhadores foram classificadas em demandas atendidas, demandas não atendidas e respostas múltiplas para situações complexas. Constatou-se que, perante as restrições do serviço, os trabalhadores apresentam marcado autogoverno para (re)criar regras de funcionamento da unidade.

PALAVRAS-CHAVE Atenção Primária à Saúde. Acesso aos serviços de saúde. Necessidades e demandas de serviços de saúde. Centros de saúde.

ABSTRACT A peculiarity of working with health is its characteristics of living work in the act, a micropolitical dimension hardly perceived by traditional evaluation instruments. Therefore, the study aimed to characterize how workers deal with the demands brought by users to a Primary Health Care Unit (PHC), through the participant observation, at a 'traditional' $\mathrm{PHC}$ of the municipality of São Paulo. The workers' responses were classified in demands met, demands no met and multiple answers to complex situations. It was found that, before the restrictions of the work, workers present a marked self-government to (re)create operating rules of functioning of the unity.

KEYWORDS Primary Health Care. Health services accessibility. Health services needs and demand. Health centers. 


\section{Introdução}

A atenção básica tem sido pensada como a principal porta de entrada para o Sistema Único de Saúde (SUS) e a coordenadora do cuidado a ser realizado nas redes de atenção à saúde, conforme recomendado pela política nacional de saúde (BRASIL, 2012; OMS, 2008). Nesse sentido, são necessários estudos que consigam caracterizar melhor se, e como, as Unidades Básicas de Saúde (UBS) garantem o 'acesso' dos usuários aos cuidados primários de saúde e, como desdobramento, aos demais níveis do sistema de saúde.

O 'problema' tomado como ponto de partida da pesquisa foi o fato bem conhecido de o trabalho em saúde, por sua característica de trabalho vivo em ato, mobilizador de tecnologias relacionais (MERHY; FRANCO, 2005), resultar em uma dimensão micropolítica dificilmente captada pelos instrumentos de avaliação tradicionais. Fazem-se necessários estudos que produzam informações mais refinadas sobre os modos como o cuidado vem sendo produzido nos serviços de saúde, em particular, o que ocorre nos encontros entre as equipes de saúde e os usuários.

A pesquisa trabalhou com o universo das demandas apresentadas pelo usuário para a equipe de uma UBS, ou seja, tudo aquilo que ele traz como solicitação ou expectativa. Cabe ao trabalhador, no momento do encontro com o usuário, lidar com suas demandas, tentando dar a melhor resposta possível a elas.

\section{Metodologia}

Do ponto de vista metodológico optou-se em trabalhar com as 'demandas' apresentadas pelo usuário, entendidas como um pedido de se consumir algo, de obter algo que o usuário julga precisar em determinado momento (consulta médica, exames, procedimentos, encaminhamentos, curativos, atestados etc.). Para caracterizar como a equipe de saúde lida com tais demandas, foi realizado estudo qualitativo de caráter etnográfico em uma UBS do município de São Paulo.

Por método etnográfico entende-se uma atividade de pesquisa no terreno, por prolongados períodos de tempo, com contato direto com o objeto de estudo, seguido pela sistematização em formato de texto da experiência [...] essa vivência só é assegurada pela observação participante 'estando lá' - passa a ser evocada durante toda a interpretação do material etnográfico [...]. (CAPRARA; LANDIM, 2008, P. 366).

Portanto, pelas características do problema de pesquisa - a dificuldade de caracterizar melhor o que se passa no encontro entre trabalhadores e usuários dos serviços -, o emprego da abordagem etnográfica justifica-se por permitir uma melhor aproximação com a micropolítica dos serviços de saúde.

Entre os métodos utilizados em etnografia, a observação participante é a técnica fundamental (LAPASSADE, 2005), caracterizando-se pela presença do pesquisador em campo por tempo prolongado. Esse método foi escolhido por permitir o mapeamento dos processos em curso na unidade de saúde estudada, dando visibilidade a aspectos de sua micropolítica, tentando caracterizar os sentidos que os trabalhadores dão para seu trabalho, no caso, como se posicionam ou que respostas produzem quando se veem diante dos usuários que, dos mais diferentes modos, expressam suas demandas.

A pesquisadora permaneceu na UBS de oito a doze horas semanais, pelo período de doze meses, observando e registrando em caderno de campo cenas do seu cotidiano, sem um foco de observação em particular.

A UBS estudada foi sugerida pela gestão regional da Secretaria Municipal de Saúde de São Paulo. Não houve um roteiro prévio de observação durante a permanência na unidade, pois o presente estudo é parte de uma pesquisa mais ampla (CECílIO, 2016), que buscava conhecer melhor o cotidiano de 
UBSs em seus múltiplos aspectos (a prática médica, os processos microrregulatórios, a prática dos agentes comunitários de saúde etc.), desenhando uma 'cartografia' a partir de seus fluxos, encontros e processos de trabalho (PASSOS; KASTRUP; TEDESCO, 2014). O artigo apresenta o resultado de uma dissertação de mestrado (MELO, 2015) que, tendo tomado, especificamente, como problema a invisibilidade do encontro entre trabalhador e usuário para o gestor, fez uma seleção de registros de cenas nas quais era possível identificar o usuário apresentando alguma demanda (consulta médica, fornecimento de medicamentos, algum tipo de procedimento etc.) no seu encontro com o trabalhador. Interessava ver em tais registros 'como' o trabalhador lidou com as demandas, em particular, o quanto ele conseguiu produzir um encontro mais ou menos cuidador, objetivo maior do estudo.

Não houve a pretensão de realizar um estudo quantitativo de tipos de respostas, tendo em vista o conjunto das cenas selecionadas. Todo o manejo de 'quantidades' e 'números' apresentados no artigo serviu apenas para compor uma espécie de painel panorâmico do funcionamento da UBS. Não foi realizada nenhuma análise estatística ou qualquer outro tratamento de caráter quantitativo dos dados produzidos, pois não era esse o objetivo do estudo.

Para análise do material selecionado, vários enquadramentos foram testados, até se obter a seguinte categorização: 'Demanda não atendida' (quando havia uma negativa pura e simples); 'Demanda atendida' (quando a demanda foi atendida tal como apresentada, ou se foi feita alguma 'proposta alternativa' para responder àquela demanda); 'Respostas múltiplas para demandas complexas' (aquelas situações de demandas múltiplas, complexas, nas quais o trabalhador buscou dar resposta para algumas delas, negou outras, fez a 'gestão das regras', adotando certas flexibilizações em algumas situações etc.). Nesta última categoria é que é possível revelar, de modo mais nítido, a criatividade do trabalhador, inclusive no manejo das regras, embora isso esteja presente nas outras categorias também.

A pesquisa foi aprovada pelo Comitê de Ética em Pesquisa da Universidade Federal de São Paulo, através do parecer n ${ }^{0} 655.842$.

\section{A unidade de saúde estudada: quando os parâmetros oficiais não captam as dificuldades de atendimento vividas pela população}

Em São Paulo, várias UBSs seguem operando no modelo denominado UBS 'tradicional', que compreende unidades organizadas sob o modelo da Ação Programática em Saúde, priorizando os programas de saúde da criança, saúde da mulher, saúde do adulto, saúde mental, saúde bucal e programas especiais para o atendimento à tuberculose e à hanseníase, com foco na promoção e na prevenção à saúde (MARSIGLIA, 2008).

Mesmo após a definição pelo Ministério da Saúde da Estratégia Saúde da Família (ESF) como sua opção preferencial de organização da atenção básica, em 2014, o município de São Paulo ainda mantinha 169 das suas 451 UBSs operando no modelo dito 'tradicional' (SÃO PAULO, 2015).

Além dos diferentes modelos assistenciais atuando no município de São Paulo, coexistem diferentes modelos de gestão, sendo possível encontrar unidades geridas pela administração direta e outras geridas em parceria com diferentes instituições privadas.

$\mathrm{Na}$ área da atenção básica paulistana, foi criada, em 2005, a AMA (Assistência Médica Ambulatorial), com foco nos atendimentos de urgência de baixa e média complexidades. No ano de 2013, havia 116 AMAs no município. Alguns estudos apontam a fragmentação criada no atendimento da atenção básica com a implantação da AMA e defendem a 
prática de atendimento à demanda espontânea nas próprias UBSs, conforme já acontece na prática cotidiana das unidades, inclusive na UBS estudada (SÃO PAULO, 2015; PUCCINI, 2006; BRASIL, 2013): A UBS estudada opera no 'modelo de UBS tradicional', ou seja, não possui ESF. A gestão é feita de forma direta pelo município, embora a unidade abrigue um NIR (Núcleo Integrado de Reabilitação) gerido pela Supervisão Regional de Saúde Sudeste, onde trabalham psicólogos, terapeuta ocupacional, fonoaudióloga e fisioterapeuta, contratados por uma entidade parceira. A porta de entrada para o NIR é feita por meio da regulação municipal. As demandas de atendimento no NIR geradas na própria unidade seguem a mesma regra.

$\mathrm{O}$ atendimento ao público é realizado de segunda à sexta-feira, das $7 \mathrm{~h}$ às $19 \mathrm{~h}$. A equipe é composta por uma gerente, dois clínicos gerais, três pediatras, dois ginecologistas, um psicólogo, duas enfermeiras, dois fisioterapeutas, duas fonoaudiólogas, uma terapeuta ocupacional, uma farmacêutica, três odontólogos, uma educadora e uma assistente social. A equipe técnica de enfermagem é composta por oito profissionais, sendo três técnicos em saúde, dois técnicos em farmácia e três profissionais de apoio ao consultório odontológico. Catorze profissionais atuam na área administrativa. A unidade conta com dois vigilantes e dois auxiliares de serviços gerais.

Sua área de cobertura abrange cerca de vinte e dois mil habitantes, sendo que há uma evidente insuficiência de profissionais para atender às demandas da população, em particular, por consultas médicas.

No início da pesquisa no campo, o prazo médio do agendamento para consulta nas clínicas básicas (pediatria, gineco-obstetrícia e clínica médica) era de noventa dias. Esse tempo, no entanto, camuflava as idas e vindas dos usuários para conseguir realizar, de fato, o agendamento. Nos dias de agendamento, a fila dobrava a esquina, e havia usuários chegando antes das $5 \mathrm{~h}$ da manhã para garantir a marcação de sua consulta.
A unidade buscou alternativas para resolver o problema das filas, como aumentar o quantitativo de pessoal para realizar os agendamentos, trocar o dia da agenda, mas, como o problema estava vinculado à baixa oferta de atendimento médico da unidade, as estratégias nunca surtiam o efeito desejado. Como não foi possível solucionar o problema do excesso de demandas para agendamento das consultas médicas, a agenda passou a não ter dia certo para abrir, transformando-se em uma loteria para os usuários. Os usuários que desejam agendar consultas médicas precisam 'ficar passando' para verificar o dia em que a agenda estará aberta.

Durante o período de observação, pudemos constatar que a unidade ficou sem pediatra ou com apenas uma pediatra às terças-feiras; o psiquiatra saiu da unidade e nunca foi reposto; o grande gargalo da unidade era a falta de clínico geral, pois contava apenas com um médico, que atendia de $2^{\mathrm{a}}$ a $6^{\mathrm{a}}$ pela manhã, e com a uma médica, que atendia apenas às sextas-feiras pela manhã, 'cedida' por uma unidade vizinha. A equipe conseguiu uma composição mais favorável, conforme pudemos constatar em visita à unidade após o termino da investigação.

Se utilizados os dados da Portaria $n^{0} 1.101 /$ GM, de 12 de junho de 2002, em vigência no período do estudo, havia um déficit aproximado de $54 \%$ de oferta de consultas (BRASIL, 2002). Se utilizados os parâmetros estabelecidos pela recente Portaria GM/MS n ${ }^{\circ}$ 1.631/ GM, de 1 de outubro de 2015, a capacidade da unidade também estava abaixo do recomendado quando da realização da pesquisa. A aplicação de parâmetros oficiais não consegue captar as variações constantes da composição da equipe (demissões sem reposições ou a inesperada chegada de um novo profissional, por exemplo). De fato, não há parâmetro com sensibilidade suficiente para captar ou revelar os dramas dos usuários no dia a dia, que ficaram mais visíveis no correr da observação de campo. 


\section{Resultados e discussão}

Foram selecionadas 128 cenas que registram encontros entre trabalhadores e usuários, tendo como critério de inclusão aquelas cenas nas quais era posto, de maneira clara, algum tipo de demanda. Dessas, 77 são registradas na recepção central ou no 'balcão de regulação', sendo que as demais ocorreram nos diversos espaços da UBS, o que já permite afirmar que os usuários se utilizam de vários 'pontos' para expressar suas demandas, além da recepção.

A maior procura ainda é por consultas médicas. Foram registradas 55 demandas de consultas para os médicos da atenção básica (pediatra, clínico geral e ginecologista) e mais 10 para médicos especialistas, totalizando 65 das 128 demandas registradas. Vê-se, aqui, como se aplicam as considerações de Cecílio (2001) sobre a 'tradução' mais frequente que os usuários fazem de suas necessidades de saúde em demandas por consultas médicas.

Com um quadro de oferta de atendimento médico sempre inferior à demanda, pacientes que não conseguem marcar as consultas desejadas (o que acontece de modo frequente) são orientados a tentar os 'encaixes' diários. Isso significa chegarem cada vez mais cedo à unidade para colocar o nome na fila de espera e aguardarem vagas decorrentes de pacientes que faltam às consultas agendadas. Uma luta diária.

Na recepção, há um 'calendário extra para agendamento dos pacientes'. Além da agenda oficial no computador, foi criada uma agenda paralela com os encaixes do dia e com 'encaixes pré-agendados' pela própria unidade, $o$ que é uma contradição, em termos.

A equipe da recepção trabalha com alguns critérios para fazer os encaixes. Para as ginecologistas, por exemplo, são agendadas preferencialmente as gestantes ou casos urgentes. Já para o clínico geral, são agendados os casos em que os exames dos pacientes estão alterados e os casos que são considerados urgentes. [o recepcionista] me explica a política do encaixe: 'está vendo esta agenda? É do clínico geral. Ele atende dezesseis pacientes, mas como muitos faltam, deixamos as pessoas que querem passar no médico aguardando, caso haja vaga para encaixe. Espera-se quinze minutos do horário agendado. Se o paciente não chegar, perde a vaga.' Há seis pacientes esperando pelo encaixe. Caso a caso, é explicado que só passarão se algum paciente faltar, 'mas sempre falta'. Há um acordo com o médico quando há casos mais graves. Eles colocam, às vezes, até dezoito pacientes, mas 'ficam devendo pra ele', e no dia seguinte ele atende apenas catorze. Quando a fila do encaixe já está grande, sugere que o paciente chegue mais cedo amanhã para 'tentar o encaixe'.

Na unidade, a equipe da recepção funciona como um 'filtro' entre a demanda da população e a sua capacidade de atendimento real. O protagonismo dos trabalhadores da recepção tem grande peso na definição sobre o acesso ou não à UBS. Esse papel de gatekeeper é fonte de muito sofrimento para os trabalhadores. Essa defasagem entre a demanda e a capacidade de oferta da unidade é a moldura da categorização que se adota para organizar o material empírico produzido na observação participante: 'demanda atendida', 'demanda não atendida' e 'respostas múltiplas para demandas complexas'.

\section{Demanda atendida}

O usuário que se dirige a uma UBS espera encontrar a solução para o problema de saúde que o incomoda. Mesmo quando uma demanda trazida pelo usuário é atendida, como na cena abaixo, pode estar escondendo as idas e vindas dos usuários em busca de atendimento:

Senhora tem intenção de marcar consulta com o clínico geral, já tinha ficado na fila na quarta-feira passada, mas a agenda não abriu. Desta vez, dormiu na casa da irmã, que é na rua da unidade, e chegou às $4 h 40$. 
O protagonismo do trabalhador é, em algumas situações, primordial para o atendimento das demandas, como na intervenção da recepcionista na cena abaixo:

Tem um senhor bem magro aguardando encaixe para o clínico geral, e a recepcionista fica preocupada, pois não sabe se faltará gente o suficiente para conseguir encaixá-lo. Ela vai à sala do médico, e ele autoriza o encaixe. Ela dá pulos de alegria!

Na cena a seguir, podem ser notados três elementos recorrentes nesses encontros: (1) a influência do médico no trabalho dos demais membros da equipe ao limitar o número de consultas; (2) o caráter subjetivo na busca de soluções para as demandas trazidas pelos usuários, como no caso da recepcionista Marcília, que opta por seguir a regra de forma mais rígida, enquanto a outra recepcionista flexibiliza a mesma regra para promover o atendimento que julga necessário; (3) a frequente tensão na recepção, provocada pela utilização do mecanismo de encaixe. Nesta cena, ainda merece destaque o comentário da recepcionista sobre a forma de utilização dos serviços pelo usuário, trazendo à tona a 'confusão' de papéis entre o uso da UBS e da AMA.

O paciente insiste em passar no clínico geral, pois está com os exames alterados. Depois de muita insistência, a recepcionista pede que ele converse com a enfermeira. São cerca de 07h30min, e já são dezesseis pacientes aguardando para passar com o clínico. Desses, apenas quatro foram agendados no sistema, e os demais são encaixes. Ela explica que alguns pacientes foram pré-agendados pela própria unidade por terem exames alterados. Com a permissão para o encaixe, ficam dezessete. A permissão foi dada por outra recepcionista, e não pela enfermeira.

A recepcionista Marcília comenta que vai acabar esta política do encaixe. O paciente já chega achando que tem direito a encaixar. Não é bem assim. Os médicos reclamam. Muitos não são urgências, mas querem encaixe para pegar atestado, mostrar exame, autorização para cirurgia, trocar receita. Eles não querem ir na AMA, preferem passar aqui, fala que lá não é bem um atendimento... é claro que é.

A cena seguinte mostra duas questões. A primeira é a insegurança do trabalhador sobre sua possibilidade de dar uma resposta ao que o usuário demanda, como se fosse um 'jogo de final aberto', enfrentado diariamente. A segunda mostra o vínculo estabelecido entre o usuário e a médica, corroborando que o usuário deseja ser atendido pelo profissional de sua confiança, que já conhece o seu histórico clínico. Assim, nos momentos de agravamento do seu quadro, ele não deseja ser encaminhado para outro serviço.

\begin{abstract}
A paciente quer passar com a ginecologista, mas a recepcionista avisa que já tem muito encaixe para hoje, que ela irá colocar o nome da paciente na lista, mas não pode garantir, pois as prioridades são as gestantes. A paciente questiona o critério, está com uma infecção e não aguenta de dor. Poderia ir ao Pronto atendimento, mas faz acompanhamento com a Dra. Vania e, inclusive, tem resultados dos exames para mostrar para médica, portanto, acredita que o melhor é passar com ela, que já vem acompanhando.
\end{abstract}

A cena acima, assim como várias outras, mostra bem como o protagonismo do usuário parece ser elemento decisivo na construção de soluções, mesmo que, para que sua solicitação seja atendida, tenha que pressionar o trabalhador. Poderia ser dito que os usuários, através de sua presença e de suas pressões, modelam, em boa medida, o funcionamento dos serviços de saúde, e isso fica bastante claro, em mais de uma situação, no correr da observação participante.

Na cena registrada na farmácia, é possível observar como o excesso de regras criadas para o melhor controle de insumos pode ser 
um impeditivo para o bom cuidado, embora, por vezes, o trabalhador opte por quebrar a regra para garantir que o paciente receba a medicação de que necessita.

[terça-feira] Chega um senhor que os 30 dias da última retirada do medicamento vence na segunda-feira, ela pede para ele retornar na sexta e argumenta: 'na sexta vou fazer hemodiálise, na segunda também não posso'. Ela entrega a medicação e comenta: 'não posso deixar ele sem os remédios, ele vai realizar hemodiálise. E se os remédios acabarem?'.

Do que foi visto até agora, é possível afirmar que, mesmo nas cenas consideradas como 'Demanda Atendida', há um grau de incerteza, de acaso, que traz muita insegurança para o trabalhador e insatisfação para o usuário.

Pode-se verificar que para a demanda ser atendida é fundamental haver oferta para tanto. O estudo permite caracterizar situações nas quais o trabalhador vai viabilizando 'ofertas alternativas' para, de algum modo, responder às demandas dos usuários, evitando dizer um simples 'não'. Essas ofertas podem estar na própria unidade, por meio do melhor aproveitamento dos recursos existentes, ou podem ser encontradas na rede de saúde pública, como no caso dos encaminhamentos para as unidades da AMA.

Às vezes, o trabalhador opta por quebrar fluxos formais do sistema de saúde para proporcionar cuidado ao usuário, de modo que muitas soluções são encontradas ad hoc.

\section{Demanda não atendida}

Nesse bloco, são mostradas cenas nas quais o usuário, além de ter sua demanda negada por vários motivos, vai embora sem ter nenhuma alternativa oferecida além da resposta 'vai passando para verificar quando a agenda abre'. Essa incerteza quanto ao atendimento é, sem dúvida, um grande problema enfrentado pelos moradores da área de referência da UBS estudada. E fonte de tensão para os trabalhadores, principalmente os da recepção.

A falta de médicos é o principal motivo para o não atendimento das demandas dos usuários, como visto antes. É frequente o vai e vem dos usuários para conseguir acesso à consulta médica desejada.

Senhora diz que está vindo pela terceira vez tentar encaixe com o clínico geral ou mesmo agendar uma consulta, e comenta: 'mas nunca a agenda está aberta'.

Devido à centralidade do médico nos procedimentos de saúde, ele torna-se o profissional essencial para o andamento de várias atividades na unidade, já que há a exigência formal da prescrição médica para retirada de medicações, realização de exames e encaminhamentos para outros profissionais. A falta da prescrição gera o não atendimento de diversas demandas na unidade.

Senhora pergunta se tem fisioterapeuta na unidade, explica que a sogra sofreu uma queda e quebrou o pulso. Por enquanto, ela tem feito os procedimentos com médico particular, mas está ficando muito caro. A recepcionista diz que sim e explica o procedimento para conseguir vaga. Primeiro passa com o clínico (mas não está agendando, por enquanto. Caso ela queira tentar encaixe, deve chegar cedo), ele encaminha para o ortopedista, que, então, a direcionaria para fazer fisioterapia. E que, se tivesse sorte, poderia ser na unidade (ou não).

A 'politica de encaixe' tem a intenção de aliviar o sofrimento da população causado pela falta de atendimento médico, procurando um melhor aproveitamento dos profissionais presentes. Essa política, no entanto, gera uma grande ansiedade e insatisfação nos usuários.

A paciente chegou às $6 \mathrm{~h}$ para tentar encaixe com a ginecologista, ficou com o nome na lista de espera, porém, após as $10 \mathrm{~h}$ horas, sem sucesso, desistiu. Nesse dia, poucas pacientes faltaram à consulta. 
Essa incerteza sobre o atendimento gera momentos de tensão entre os usuários e a equipe da recepção.

A recepcionista fala da dificuldade em trabalhar sob tanta pressão dos usuários e que tem medo de ser agredida fisicamente. Comenta que agora os encaixes estão difíceis, pois, como os usuários não conseguem novas consultas, não têm faltado às consultas agendadas. Nesta tarde havia sete pessoas para encaixe com a ginecologista, e somente três ausências, assim, os demais tiveram que ir embora sem conseguir atendimento.

Uma paciente jovem reclama. Diz que falaram para ela esperar que seria atendida. Ela chegou à unidade às 11 h e já eram 15 h40 quando avisaram que ela não conseguiria.

A recepcionista é incisiva em dizer que todos foram alertados que era encaixe, portanto podiam ou não conseguir o atendimento médico. A paciente afirma que não, que para ela estaria certo que passaria.

O recepcionista comenta: 'não dá para deixar o pessoal esperando sem saber se será atendido. A partir de um número de pessoas já temos que dispensar. Hoje mesmo eu dispensei várias... a gente explica que não podemos dar certeza do atendimento, mas eles não entendem ou não querem entender'.

Cabe à recepção um papel importante na 'triagem' dos usuários, muitas vezes, sendo decisiva para definir quem tem acesso ou não ao atendimento. A falta de conhecimento técnico pelas recepcionistas pode ser um problema para os usuários que necessitam de um atendimento diferenciado.

Chama minha atenção um casal boliviano. A esposa grávida de sete meses está com dor. 0 diálogo é bem truncado entre o recepcionista e o marido (eu não consegui entender o motivo). Após a insistência do marido, o recepcionista orienta a aguardarem na frente da sala da enfermeira.

O marido reclama que já foi três vezes na UBS e não é atendido, o recepcionista explica ao marido 'que foi atendido, sim, eu atendi! Só não resolveu o problema dele'.

Mesmo considerando a recepção como um espaço de escuta e criação de alternativas, há limites para a autonomia dos trabalhadores, considerando que ele deverá seguir um conjunto de normas e procedimentos preestabelecidos.

Percebo, novamente, a presença de uma senhora que já esteve lá pela manhã. Após, fico sabendo que é um encaixe para a filha com a ginecologista. Mais uma vez, é explicado que é encaixe, que deve aguardar surgir vaga e que a prioridade são as gestantes.

A recepcionista (Bete) vai verificar se as gestantes já estão aguardando em frente à sala da ginecologista e demora um pouco. Neste ínterim, a filha da senhora chega e descobre que é um encaixe e que tem que aguardar, sem a certeza de que será atendida. Fica muito nervosa e pede para tirar o nome dela da lista. A mãe tenta amenizar a situação: 'a recepcionista falou de manhã que era certeza que atendia, o caso da minha filha é uma urgência, ela está com um nódulo e precisa ver isto'. A recepcionista (Bernadete) ouve e observa, mas não se pronuncia, assim, a filha decide: 'pode tirar o meu nome da lista, eu tenho que ir trabalhar'.

O fato de o usuário ser de outra área de cobertura é um dos motivos para a negativa do atendimento. A territorialização (BRASIL, 2012), quando trabalhada de forma muito rígida, impede que o usuário seja atendido pelo profissional de sua escolha. 
Mãe deseja marcar consulta com o Pediatra. Diante da oferta da vaga com o Dr. Valter, questiona:

Mãe - não tem outro pediatra?

Recepcionista - Quantos anos tem a criança?

Mãe - Cinco meses.

Recepcionista - então, é somente ele ( a mãe fica confusa, então, a recepcionista esclarece): tem a Dra. Aline, que é Hebiatra, atende os jovens de 12 a 17 anos. Pode marcar com o pediatra?

Mae - Não, com ele não, vou marcar em outra unidade.

A Recepcionista informa - Se a referência da moradia da senhora é esta unidade, não vai conseguir agendar em outra.

Pergunto a mãe como ela irá fazer para acompanhar o bebê?

Mãe - eu pego o endereço das minhas irmãs e marco em outra unidade, me viro..., mas com ele eu não passo.

As regras que visam a um maior controle de insumos também são motivos para o não atendimento das demandas, principalmente na farmácia.

Mãe com o bebê, que toma medicação controlada, não tem como checar e, portanto, não pode fornecer a medicação. A mãe alega que o bebê não pode ficar sem a medicação, e ela não tem mais remédio em casa. A atendente fica preocupada e tenta resolver. A mãe fala que tem a última receita em casa com a data do recebimento. A atendente pede para ela buscar em casa, pois o posto fica aberto até as sete.

Diante da demora e da incerteza, muitos pacientes saem da unidade sem ao menos enunciar suas demandas. Percebe-se que, quando a unidade não tem como atender à(s) demanda(s) dos usuários, a ‘solução’ possível é que ele se desloque até outro ponto da rede. Assim, muitas vezes, os usuários são orientados a procurar a AMA por falta de atendimento médico na unidade. Vale ressaltar que esses 'encaminhamentos' são realizados de maneira informal, o que contraria a proposta original do serviço, como disposto nas diretrizes da AMA (SÃO PAULO, 2015).

Como resumo desse item, pode-se dizer que o não atendimento da demanda trazida pelo usuário pode ter várias causas: 1. A demanda por serviços, especialmente por consultas médicas, é sempre maior que a disponibilidade de recursos; 2 . O despreparo técnico do pessoal da recepção, inclusive o desconhecimento de possibilidades de ofertas dentro da própria unidade; 3 . A falta de ofertas alternativas de atendimento, ainda muito centrado na figura do médico; 4. A rigidez do processo de territorialização; 5. O posicionamento e o protagonismo dos usuários quando recusam a oferta que é feita, se avaliam que ela não coincide com sua demanda de atendimento por algum profissional específico; 6. A existência de uma lógica programática (TEIXEIRA; SOLLA, 2006; BRASIL, 2012; SÃO PAULO, 2010) que dificulta o acesso de pacientes que não se encaixam nas prioridades estabelecidas pelo programa; 7. A existência de regras para entrega de medicamentos e insumos (SÃO PAULO, 2010); 8. A falta de alguns insumos.

\section{Respostas múltiplas para demandas complexas}

Nesse bloco estão as cenas que, por apresentarem demandas múltiplas e complexas, resultam em desfechos ambíguos, sendo que algumas demandas são atendidas e outras não, e, em algumas situações, uma oferta diferente é apresentada pelo trabalhador. São situações bastante frequentes e que permitem observar aspectos importantes da micropolítica da unidade (CECCIM; 
MERHY, 2009; MERHY; FRANCO, 2005), especialmente as construções realizadas por trabalhadores e usuários.

Há situações tipo 'escolha de Sofia', nas quais o próprio usuário, trazendo demanda de três pessoas diferentes, deverá decidir quem mais precisa de atendimento médico.

Uma senhora com idade bastante avançada aguarda para agendar consulta para uma irmã de fé, mesmo com dificuldade em ficar muito tempo em pé porque está doente. Ela se compadeceu da vizinha que cuida de duas irmãs, uma na cadeira de rodas e a outra com depressão. A 'moça' já veio marcar a consulta na UBS, mas não conseguiu e fica muito difícil sair de casa, pois não pode deixar as irmãs sozinhas. A senhora espera agendar consulta para as três, já que a 'moça', mais um informe, 'Não vai poder agendar para mais de uma pessoa. Cada pessoa só terá direito a um agendamento'. A recepcionista Nelma me explica: 'é um agendamento por família. Eles têm que escolher quem precisa mais'.

Cecílio (2012) já havia apontado para o que seria uma disjunção dos tempos do gestor, do trabalhador e do usuário, ressaltando como o tempo assume dimensões diferentes para os vários atores, em particular, o quanto a vivência da doença resulta numa vivência do tempo, que é da ordem da urgência, do 'aqui e agora', que quase nunca pode ser contemplada pelos serviços de saúde.

[21 de maio] Encontro uma moça com um bebê no colo. Acompanhei a consulta dela ainda gestante com a enfermeira. Ela conta que a criança nasceu de parto normal e foi tudo bem, mas a criança teve infecção no coto umbilical e ficou internada por 15 dias tomando antibióticos. Comenta que, por causa da internação, perderam a consulta, que é pré-agendada quando sai da maternidade, e, por isso, veio remarcar hoje. 'Liguei avisando que não poderia comparecer'. Agora está com dor no local dos pontos, acredita que podem ter infeccionado, mas a consulta com a ginecologista é somente para junho.
Em várias situações cotidianas, nas quais o trabalhador se vê diante de casos complexos, caracterizados por um conjunto de várias demandas trazidas simultaneamente pelo usuário, observam-se duas possibilidades mais comuns de desfechos: ou o trabalhador faz um recorte (seleciona) de uma determinada demanda para a qual tem uma resposta factível e, de certa forma, 'despreza' as demais, ou usa sua capacidade criativa para atender, pelo menos parcialmente, ao conjunto de demandas apresentadas. Essas cenas são captadas em espaços que propiciam a escuta, ou seja, de um modo geral, não são realizadas na recepção, já que esse é um ambiente de pressão, alta rotatividade de atendimentos (pressa) e de falta de privacidade. $\mathrm{E}$, também, são cenas reveladoras sobre as escolhas do usuário, que pode rejeitar as saídas oferecidas pelo trabalhador se não forem exatamente o que ele deseja.

\section{Conclusões}

Vivenciar o cotidiano das equipes revelou-se muito produtivo. Mesmo reconhecendo que demanda em saúde não é a mesma coisa que necessidade de saúde, a reflexão propiciada por um olhar mais cuidadoso sobre as demandas dos usuários, especialmente como elas são 'manejadas' pelo trabalhador, revelou-se um poderoso analisador das relações micropolíticas da unidade de saúde, aquilo que ocorre no ponto mais capilarizado do sistema de saúde, no 'espaço intercessor' em que se dá o encontro trabalhador-usuário, independentemente do modelo assistencial adotado. Essa poderia ser considerada a maior contribuição do estudo.

Talvez seja possível afirmar que, ao operar um modelo de atenção 'tradicional', de certa forma, 'ultrapassado' quando comparado à abertura propiciada pela ESF, haveria uma perda de qualidade de atendimento para os usuários do território, o que pode ser um indicativo de inequidade no sistema, já que um 
percentual importante de unidades do município opera com a ESF. Nesse sentido, uma das conclusões do estudo é a recomendação da mudança do modelo assistencial adotado na UBS, para, entre outras coisas, haver uma ampliação do cardápio de ofertas para os usuários, na perspectiva de se reduzir a demanda por consultas médicas e se alcançar um atendimento mais integral. Sem dúvida, o 'modelo tradicional', ainda operado pela UBS, muito centrado na figura do médico, em boa medida, agrava o problema da falta de recursos. Por exemplo, a utilização da estratégia de acolhimento poderia ser uma saída viável para a unidade estudada, oferecendo um cardápio mais amplo de ofertas para os usuários, a partir de uma escuta mais qualificada das demandas apresentadas. As cenas alocadas na categoria 'respostas múltiplas para demandas complexas' são aquelas que mostram melhor os limites da unidade e as estratégias da equipe e dos usuários para enfrentá-las. É nesse espaço que se pode observar a potência do espaço intercessor trabalhador-usuário, mostrando a capacidade de mobilização da equipe, os arranjos realizados etc. Um espaço que, muitas vezes, é, de modo surpreendente, de invenção e cuidado. Ali é possível reconhecer a ação cuidadora da equipe para a resolução dos problemas trazidos pelos usuários, inclusive 'quebrando' as regras da gestão, exercitando sua 'inteligência astuciosa'.

Tais encontros permitem ter mais clareza sobre o quanto o espaço intercessor é constituído e atravessado por várias lógicas que definem o quanto o trabalhador poderá ou não atender às demandas que lhe são apresentadas, entre elas, o modo de operar do modelo biomédico centrado no corpo doente, cada vez mais produtor de exames e utilizador de fármacos. Tal modelo segue hegemônico ainda na atenção básica, apesar de todas as possibilidades de cuidados alternativos; a formação técnica e o sentido ético que o trabalhador dá ao seu trabalho; o conjunto de diretrizes, normativas e regras de utilização dos serviços delimitando fortemente o campo de ação (e de 'possíveis') do trabalhador, incluindo-se, aqui, a rigidez na definição da regionalização e a consequente adscrição de clientela, e uma forte valorização dos princípios da Programação em Saúde do Ministério da Saúde; as condições materiais de trabalho, que circunscrevem os limites do trabalhador para fazer frente às demandas apresentadas.

O artigo aponta elementos para uma melhor compreensão de como é intensa e contraditória a vida cotidiana de uma UBS para fazer frente às demandas dos usuários. Mostra como os trabalhadores operam com os limites impostos pelas condições objetivas de trabalho, mas, também, com elementos não tão facilmente identificáveis que são da ordem da subjetividade e do sentido ético dado ao trabalho. Como disse a recepcionista para a pesquisadora: "Quem sabe você vendo e anotando...”, acreditando que dar visibilidade para esse cotidiano tão duro em outros espaços talvez possa contribuir para promover alguma mudança. Trazer o cotidiano da unidade de saúde para um trabalho acadêmico poderá, em alguma medida, contribuir para dar visibilidade ao que ocorre de modo silencioso e anônimo na unidade? O título do trabalho, 'Nem sempre sim, nem sempre não' expressa, portanto, que, muito frequentemente, o resultado do encontro trabalhador-usuário não é, de saída, previsível quando se trata de acesso ao serviço, configurando-se em uma situação de 'meia-cidadania' para aqueles que dependem do SUS, especialmente da atenção básica. 'Meia-cidadania' porque o acesso é, em princípio e por garantia constitucional, de caráter universal, mas, na prática, o cidadão que depende do SUS para receber a atenção à sua saúde não tem o acesso garantido de saída, já que este dependerá de um conjunto de fatores que não estão previamente dados.

Como limitação do estudo, poderia ser apontado o fato de ter sido realizado em uma UBS que adota um modelo de atenção, 
em princípio, em 'extinção'. Por outro lado, seria possível dizer que essa 'invisibilidade' dos encontros dos trabalhadores com os usuários, em particular, o quanto resultam em mais ou menos cuidado, é uma questão importante para quem se ocupa da gestão em saúde, independentemente do modelo assistencial adotado e mesmo do regime jurídico vigente, de recorte mais ou menos privatizado. Enfim, o estudo mostra o quanto o SUS real, aquele vivido pelas pessoas movidas por suas necessidades, é uma construção diária, tensa, disputada no encontro diário entre trabalhadores e usuários ali no serviço de saúde.

\section{Colaboradores}

Melo, S. M., Cecílio, L.C.O. contribuíram substancialmente para a concepção, análise, interpretação dos dados e aprovação da versão final do manuscrito. Andreazza, R. contribuiu para a concepção, análise, interpretação dos dados e revisão crítica do conteúdo.

\section{Referências}

BRASIL. Ministério da Saúde. Portaria nº 1101/GM, de 12 de junho de 2002. Diário Oficial [da] União, Brasília, DF, 12 jun. 2002. Disponível em: < http:// www.saude.ba.gov.br/direg/images/legislacao/portaria_1101_12_06_02.pdf>. Acesso em: 10 dez. 2015.

Ministério da Saúde. Portaria GM/MS nº 1.631/GM, de 1 de outubro de 2015. Diário Oficial [da] União, Brasília, DF, 1 out. 2015. Disponível em: $<$ http://www.poderesaude.com.br/novosite/images/ publicacoes_02.10.2015-III.pdf $>$. Acesso em: 13 set. de 2016.

Ministério da Saúde. Secretaria de Atenção à Saúde. Acolhimento à demanda espontânea: queixas mais comuns na Atenção Básica. Brasília, DF: Ministério da Saúde, 2013. (Cadernos de Atenção Básica n. 28; v. II).

Ministério da Saúde. Secretaria de Atenção à

Saúde. Política Nacional de Atenção Básica. Brasília, DF,
2012. Disponível em: <http://189.28.128.100/dab/docs/ publicacoes/geral/pnab.pdf>. Acesso em: 10 dez. 2014.

CAPRARA, A.; LANDIM, L. P. Etnografia: usos, potencialidades e limites na pesquisa em saúde. Interface (Botucatu), Botucatu, v. 12, n. 25, p. 363-376, abr./jun. 2008.

CECCIM, R. B.; MERHY, E. E. Um agir micropolítico e pedagógico intenso: a humanização entre laços e perspectivas. Interface (Botucatu), Botucatu, v. 13, supl. 1, p. 531-542, 2009

CECÍLIO, L. C. O. (Coord.). A Atenção Primária como estratégia para a (re)configuração das Políticas Nacionais de Saúde: a perspectiva de seus trabalhadores e usuários. 2016. Disponível em: < http://www. bv.fapesp.br/pt/auxilios/81820/a-atencao-primaria-a-saude-como-estrategia-para-reconfiguracao-do-sus-a-perspectiva-de-seus-profi/>. Acesso em: 30 mar. 2017. 
Escolhas para inovarmos na produção do cuidado, das práticas e do conhecimento: como não fazermos “mais do mesmo". Saude Soc., São Paulo, v. 21, jun. 2012. Disponível em: <http://dx.doi.org/10.1590/S010412902012000200003>. Acesso em: 21 ago. 2013.

As necessidades de saúde como conceito estruturante na luta pela integralidade e eqüidade na atenção. 2001. Disponível em: <http://www.uff.br/pgs2/textos/ Integralidade_e_Equidade_na_Atencao_a_saide_-Prof_Dr_Luiz_Cecilio.pdf>. Acesso em: 10 ago. 2015.

LAPASSADE, G. As Microssociologias. Brasília, DF: Liber Livro Editora, 2005.

MARSIGLIA, R. M. G. (Coord.). Integralidade e Atenção Primária em Saúde: avaliação da organização do processo de trabalho em unidades de saúde da Secretaria Municipal da Saúde de São Paulo. 2008. Disponível em: <http://www.cealag. com.br/Trabalhos/INTEGRALIDADE\%20E\%20 ATEN\%C3\%87\%C3\%830\%20PRIM\%C3\%81RIA\%20 EM\%20SA\%C3\%9ADE/Relat\%C3\%B3rio.pdf $>$. Acesso em: 14 maio 2015.

MELO, S. M. Nem sempre sim, nem sempre não: os encontros entre trabalhadores e usuários em uma unidade de saúde. 2015. 181 f. Dissertação (Mestrado em Ciências) - Escola Paulista de Medicina, Universidade Federal de São Paulo, São Paulo, 2015.

MERHY, E. E.; FRANCO, T. B. Trabalho em Saúde. Rio de Janeiro: EPSJV / Fiocruz. 2005.

ORGANIZAÇÃO MUNDIAL DE SAÚDE (OMS). Cuidados de Saúde Primários: agora mais que nunca. Relatório Mundial da Saúde. Lisboa: MS, 2008. Disponível em: <http://www.who.int/whr/2008/ whr08_pr.pdf $>$. Acesso em: 10 set. 2015.

SÃO PAULO (Município). Secretaria Municipal de Saúde. Plano Municipal de Saúde 2010-2013. 2010. Disponível em: <http://extranet.saude.prefeitura. sp.gov.br / planomunicipal /PlanoMunicipalSaudeSMSPMSP_2010-2013.pdf>. Acesso em: 22 set. 2013.

Secretaria Municipal de Saúde. Indicadores para Diagnóstico Sintético da Saúde. Cidade de São Paulo 2004-2011. São Paulo, 2013. Disponível em: <https:// www.google.com.br/url?sa=t\&rct=j\&q=\&esrc $=$ s\&sou rce=web\&cd=1\&ved=0ahUKEwjChsj3Y_SAhUDgZA KHVkLCh8QFggcMAA\&url=http\%3A\%2F\%2Fsms. sp.bvs.br\%2Flildbi\%2Fdocsonline\%2Fget.php\%3Fid\%3D4304\&usg=AFQjCNHrKnHKFVOGkChXadU KscY7paHLsA\&sig2=gyNXmJKfqTFb2FVofk7C4g>. Acesso em: 10 jan. 2017.

Secretaria Municipal de Saúde. Diretrizes gerais da atenção básica. 2015. Disponível em: <http://www. prefeitura.sp.gov.br/cidade/secretarias/upload/saúde / arquivos/ama/AMA_ManualDiretrizesTecnicas.pdf>. Acesso em: 10 jun. 2015.

PASSOS, E.; KASTRUP, V.; TEDESCO, S. (Org.). Pistas do método cartográfico: a experiência da pesquisa e o plano do comum. Porto Alegre: Sulina, 2014.

PUCCINI, P. T. As unidades de assistência médica ambulatorial (AMA) do Município de São Paulo, Brasil: condições de funcionamento e repercussões sobre a atenção básica no Sistema Único de Saúde. Cad. Saúde Pública, Rio de Janeiro, v. 24, n. 12, p. 2755-2766, 2006. Disponível em: <http://www.scielo.br/pdf/csp/ v24n12/04.pdf>. Acesso em: 30 julho de 2015.

TEIXEIRA, C. F.; SOLLA, J. P. Modelo de Atenção à saúde: promoção, vigilância à saúde e Saúde da Família. Salvador: Edufba, 2006.

\footnotetext{
Recebido para publicação em agosto de 2016

Versão final em janeiro de 2017

Conflito de interesses: inexistente

Suporte financeiro: Fundação de Amparo à Pesquisa do Estado de São Paulo (Fapesp), processo no 2012/51258-5. Conselho Nacional de Desenvolvimento Científico e Tecnológico (CNPq), processo $n=483460 / 2012-5$
} 